\title{
The Role of Bone Marrow Microenvironment in Governing the Balance between Osteoblastogenesis and Adipogenesis
}

\author{
Jiao Li ${ }^{1 *}$, Xingyu Liu ${ }^{1}$, Bin $\mathrm{zuo}^{2}$, Li Zhang ${ }^{3}$ \\ ${ }^{1}$ Department of Cell Biology, Zunyi Medical College, Zunyi, China \\ ${ }^{2}$ Department of Orthopedic Surgery, Xinhua Hospital, Shanghai JiaoTong University School of Medicine, \\ Shanghai, China \\ ${ }^{3}$ Department of Orthopedics, Tenth People's Hospital, Shanghai Tong Ji University, School of Medicine, Shanghai, \\ China
}

[Received August 8, 2015; Revised December 3, 2015; Accepted December 6, 2015]

\begin{abstract}
In the adult bone marrow, osteoblasts and adipocytes share a common precursor called mesenchymal stem cells (MSCs). The plasticity between the two lineages has been confirmed over the past decades, and has important implications in the etiology of bone diseases such as osteoporosis, which involves an imbalance between osteoblasts and adipocytes. The commitment and differentiation of bone marrow (BM) MSCs is tightly controlled by the local environment that maintains a balance between osteoblast lineage and adipocyte. However, pathological conditions linked to osteoporosis can change the BM microenvironment and shift the MSC fate to favor adipocytes over osteoblasts, and consequently decrease bone mass with marrow fat accumulation. This review discusses the changes that occur in the BM microenvironment under pathological conditions, and how these changes affect MSC fate. We suggest that manipulating local environments could have therapeutic implications to avoid bone loss in diseases like osteoporosis.
\end{abstract}

Key words: osteoporosis, bone marrow microenvironment, mesenchymal stem cells, osteoblast

Formation of bone tissue in the embryo and maintenance of bone homeostasis in the adult are largely due to the activity of bone marrow (BM) stem cells called mesenchymal stem cells (MSCs). However, the dysfunction MSCs may give rise to bone diseases such as osteoporosis. A correlation between adipose accumulation in the bone marrow and a decrease in bone mass has been reported under pathological conditions associated with bone loss, such as aging, estrogen deficiency, chronic glucocorticoid (GC) treatment, and lack of mechanical loading [1-8]. This proposition is known as the fat theory for osteoporosis $[9,10]$. As both osteoblasts and adipocytes originate from MSCs, it is likely that predisposition of bone marrow MSCs to adipocyte lineage at the expense of osteoblasts is a contributing factor to this phenomenon. A growing body of evidence has confirmed the reciprocal relationship between these two lineages both in vivo and in vitro [1113]. One of the main questions remaining in the study of MSC biology is what changes MSC fate under these pathological conditions.

Like many stem cells, MSCs are located in specific microenvironments that are responsible for the maintenance of stem cell populations, their controlled proliferation, and their differentiation into multiple lineages $[14,15]$. $\mathrm{BM}$ microenvironment, an *Correspondence should be addressed to: Jiao Li, Ph.D., Zunyi Medical College, No. 201, Dalian Road, Zunyi, 563003, Guizhou, China. Email: owllj@163.com.

Copyright: ( 2016 Li J, et al. This is an open-access article distributed under the terms of the Creative Commons Attribution License, which permits unrestricted use, distribution, and reproduction in any medium, provided the original author and source are credited. 
extraordinarily heterogeneous and dynamic system, is generated by the functional relationship among different cells found in the BM via locally produced soluble factors that allow autocrine, paracrine, and endocrine activities $[14,15]$. Physiological BM provides a suitable microenvironment for osteogenesis and the maintenance of bone homeostasis. In such conditions, MSCs pass through a sequence of events ensuring proper osteoblast development in terms of phenotype and functional properties until they enter osteocyte phenotype and/or undergo apoptosis [16]. However, with advanced age, estrogen deficiency, chronic glucocorticoid treatment, and decreased mechanical load, BM microenvironment changes significantly thus providing signals that not only repress osteogenesis, but also favor adipocyte differentiation and formation [1-8]. This review discusses the factors that alters the BM microenvironment under pathological conditions linked to bone loss, and how these alterations shift MSC fate to favor adipocyte lineage over osteoblasts.

\section{Osteoblast differentiation under physiological conditions}

Using animal models, researchers found that age-related osteoporosis can be introduced in normal mice by injection of total BM cells from senile mice directly into the BM cavity of normal recipients [17-19]. Similarly, the osteoporotic phenotype of senile mice was ameliorated by intro-BM injection of normal allogenic BM cells into senile recipients [17-19]. These findings demonstrated that bone tissue homeostasis is largely regulated and maintained by the BM microenvironment. Physiological BM microenvironment provides signals from local/systemic factors and extracellular matrix, which are critical for MSC maintenance and osteogenesis [20]. Before committing to osteogenic differentiation in the BM [16], MSCs undergo several rounds of proliferation $[16,21,22]$. Then, the pre-osteoblasts are mobilized to the bone surface, which is a crucial step in the maturation and formation of mineralized tissue [23]. Indeed, osteoblast maturation is inhibited until the pre-osteoblasts migrate to the bone forming surface $[20,23]$. Transforming growth factor- $\beta 1$ (TGF- $\beta 1$ ), which is one of the most abundant cytokines in the BM, induces the migration of preosteoblasts to bone forming surface [23]. This surface provides a stiff, elastic microenvironment that immediately triggers focal adhesion kinase (FAK) pathway in attached pre-osteoblasts thus leading to cytoskeleton rearrangement and a more spread out cell shape $[24,25]$. Locally enriched soluble factors such as the bone morphogenetic proteins (BMPs), insulin-like growth factor (IGF), Wnts and fibroblast growth factors (FGFs) secreted by bone cells further activate osteogenic signals such as Wnt, ERK, JAK-STAT, MAPK and PI3K/Akt. These signals trigger pre-osteoblast maturation that eventually leads to the formation of mineralized tissue [26-31].

On the other hand, adipocytic differentiation of MSCs in physiological BM is restricted. Osteogenic signaling factors such as TGF- $\beta 1$ and Wnt have been reported to inhibit adipogenesis [32-34] by repressing the expression and/or activities of key adipogenic transcriptional factors, CCAAT/enhancer binding protein alpha $(\mathrm{C} / \mathrm{EBP} \alpha)$ and peroxisome proliferator-activated receptor gamma $(\operatorname{PPAR} \gamma)$ [32-34].

\section{How pathological conditions change the BM?}

Age-related bone loss begins as early as 20 years in young adults, long before hormonal changes can affect bone strength and density [35]. Recent studies have shown that oxidative stress in aging mice may be an important pathogenic mechanism that leads to age-related bone loss and reduced bone strength. In addition, loss or reduced levels of sex hormones in aging mice accelerates the effects of aging on the bone by decreasing defense against oxidative stress [36]. Even though it is not clear whether oxidative stress is the main reason for age-related bone loss in humans, an increasing number of experimental and epidemiological evidences link osteoporosis to accumulated reactive oxygen species (ROS) in the BM [37]. These ROS not only cause tissue damage and cell senescence, but also leads to BM inflammation through redox sensitive transcriptional factors such as nuclear factor-kappaB (NF- $\mathrm{B})$ [38-40]. NF- $\kappa \mathrm{B}$ is among the most important transcription factors that respond directly to oxidative stress conditions. In resting cells, NF- $\mathrm{KB}$ proteins are sequestered in the cytoplasm through their tight association with I $\mathrm{KB}$ proteins [41, 42]. After receiving an appropriate signal, $\mathrm{NF}-\kappa \mathrm{B}$ is released from $\mathrm{I} \kappa \mathrm{B}$ and is translocated to the nucleus where it stimulates the expression of interleukin-1 (IL-1), IL-6, tumor necrosis factor alpha (TNF $\alpha$ ) and other cytokines essential to trigger an inflammatory response [42]. ROS stimulation promotes JNK/Src-mediated IKB phosphorylation, and consequently enhances the signal transduction pathways for NF- $\kappa \mathrm{B}$ activation in the cytoplasm and translocation to the nucleus [38-40]. Under physiological conditions, NF- $\mathrm{KB}$ activation in response to extracellular signals is short-lived, and the reaction stops quickly once the signal is removed [41, 42]. However, if the activation signal persists, such as accumulated ROS in aged BM, the effect of NF- $\mathrm{KB}$ signal becomes persistent thus leading to elevated levels of pro-inflammatory cytokines in the BM. Pro-inflammatory cytokines such as TNF $\alpha$, IL-6 and monocyte chemoattractant protein-1 (MCP-1) promote a cascade of events that result in the 
recruitment of inflammatory $\mathrm{T}$ lymphocyte subsets, mast cells, monocytes and macrophages from the blood [43]. These infiltrated immune cells in BM secret more proinflammatory factors and together contribute to an inflammatory microenvironment. It is known that proinflammatory cytokines such as TNF $\alpha$ and IL-1 also stimulate ROS generation through mitochondrial and NADPH oxidase system [44]. Therefore, oxidative stress and inflammation together promote a positive feedback loop that characterizes the pathological microenvironment of aged BM (Fig. 1).



Figure 1. BM microenvironment under pathological conditions. Aging-associated increase in ROS promotes NF- $\kappa \mathrm{B}$ releasing from $\mathrm{I} \kappa \mathrm{B}$ and subsequent translocation into nucleus where it binds to responsive element to activate transcription of inflammatory cytokines such as TNF $\alpha$, Il-6 and MCP-1. Elevated level of these inflammatory cytokines in BM results in immune cell infiltration from blood, such as T cells, monocytes and macrophages. CD40/CD40L mediated Cell-cell communication between T cells and $\mathrm{BM}$ stromal cells further enhances NF- $\mathrm{BB}$ signal, promoting stromal cells express more inflammatory cytokines. Additional inflammatory cytokines such as TNF $\alpha$ and IL-1 secreted from stromal cells as well as infiltrated immune cells also stimulates ROS generation through mitochondrial and NADPH oxidase system, forming a positive feedback loop that contributes to BM oxidative stress and chronic inflammation. These pathological environmental signals shift MSC fate to favor adipocytes over osteoblasts. Accumulated fat further deteriorate BM microenvironment through secreted FFAs, inflammatory cytokines and altered adipokine secretome. Besides, excessive FFAs generate more ROS while oxidation, initiating a vicious cycle that accelerates BM microenvironment deterioration. 
It is demonstrated that increased ROS and chronic inflammation are the main mechanisms that regulate agerelated bone loss and reduced bone strength. Furthermore, sex-related steroid deficiency exerts its adverse effects on bone metabolism by similar mechanisms in animal models at the molecular, cellular and tissue levels [36]. As estrogen has direct antioxidant and anti-inflammation effects, deficiency of estrogen after menopause accelerates the adverse effects of aging on bone by decreasing defense against ROS and inflammation [36, 45, 46]. A comparison of different factors in the BM fluid between the control and postmenopausal donors showed a correlation between a decrease in estrogen level and an increase in TNF $\alpha$ and IL-6 levels [47] suggesting chronic inflammation in estrogen deficiency-induced osteoporotic BM. More recent studies with ovariectomized (OVX) models provided direct evidence indicating BM inflammation as one of the main effects of estrogen-deficiency induced bone loss [48-50]. In vivo assays found that estrogen deficiency induces $\mathrm{TNF} \alpha-$ secreting T-cell expansion, which promotes BM stromal cells to secret more pro-inflammatory cytokines (IL-6, IL7 , and MCP-1) by physically interacting with these cells through the CD40/CD40L axis [48]. Depletion of TNFa [49] or CD40/CD40L [48], or blocking T cell activation [50] partly or completely overrides bone loss and low bone strength in OVX mouse models thus supporting the primary role of inflammation in estrogen deficiencyinduced osteoporosis. In vitro analysis of the molecular mechanisms underlying the anti-inflammatory effects of estrogen in secondary osteoblasts showed that estrogen activated signal inhibits NF- $\mathrm{KB}$ activity at multiple levels. First, estrogen receptor alpha (ER $\alpha)$ physically associates with NF- $\mathrm{BB}$, which inhibits trans-activation of its target genes [51-53]; second, activation of $\mathrm{ER} \alpha$ removes coactivators away from NF- $\mathrm{BB}[52,54]$; third, ER $\alpha$ inhibits I $\kappa$ B degradation, prevents NF- $\kappa B$ release from I $\mathrm{KB}$ and its subsequent nuclear translocation $[46,52,53]$. However, these in vitro studies were not performed in primary osteoblasts thus the hormone-induced tissue-specific mechanisms regulating bone loss in osteoblasts is unclear.

Moreover, evidence from pharmacological and genetic studies has supported the notions that oxidative stress and inflammation induce deleterious effects in bone, and that an increase in ROS and inflammatory cytokines represent the pathophysiological mechanisms underlying bone loss caused by alcohol exposure $[55,56]$ and chronic GC treatment [57].

Oxidative stress and chronic inflammation in pathological BM microenvironment greatly promote osteoclast differentiation and activity thus uncoupling bone resorption from formation by accelerating the former $[58,59]$. In such circumstances, the production of bone forming signaling molecules such as TGF- $\beta 1$ and BMPs are reduced [60] whereas the production of their antagonists is increased [61]. Under such conditions, it is likely that the migration to bone forming surface and the subsequent osteoblastogenesis of MSCs are severely impaired [62, 63].

Accumulated fat is found in pathological BM. As fat tissue is now considered as an endocrine organ capable of expressing and secreting many different autocrine, paracrine and endocrine factors [64], additional fat in BM has deleterious effect on the local microenvironment by releasing more free fatty acids (FFAs) and proinflammatory cytokines. In inflammatory BM, adipocyte function is affected as evidenced by the inhibition of FFAs uptake and lipogenesis. However, FFAs release is accelerated due to inflammation-induced insulin resistance and lipolysis $[65,66]$. These FFAs contribute to systemic dysfunction by generating more ROS during oxidation [66]. This cytotoxic effect of fatty acids is termed lipotoxicity [67]. Under such conditions, even preadipocytes become increasingly susceptible to lipotoxicity [68] and express more pro-inflammatory cytokines, initiating a vicious cycle that accelerates BM microenvironment deterioration (Figure 1).

\section{How pathological environmental factors affect the MSC differentiation pathway?}

ROS

High level of ROS in pathological BM is believed to be one of the main reasons for MSC apoptosis as well as osteoblastogenesis inhibition. Several mechanisms appear to be involved in this process including DNA damage [69]. In vivo studies on a DNA repair-deficient mouse model have confirmed that accumulation of DNA damage interferes with normal skeletal maintenance, leading to reduced osteoblast precursor numbers and decreased bone strength [70]. In vitro studies also found that ROS suppresses osteoblast differentiation of MSCs, manifested by a reduction in the osteoblast markers, alkaline phosphatase (ALP), collagen type I alpha I (Col1a1) and phosphorylated Runx2 [71]. On the other hand, oxidative stress itself has been shown to directly modulate adipocyte differentiation. Adipogenesis is accompanied with the generation of ROS and in turn, high dose of ROS markedly induces adipocyte differentiation [72]. Since $\mathrm{BM}$ is exposed to oxidative stress under pathological conditions, oxidative stress itself may provide a favorable adipogenic environment resulting in fat accumulation.

The above effects of ROS on osteoblast/adipocyte differentiation are mediated, at least in part, by redoxsensitive regulators in MSCs during oxidative stress [73, 74]. One of the most extensively studied factors is a NADdependent class III histone deacetylase, Silent 
Information Regulator T1 (Sirt1), which is a wellconserved sirtuin family of longevity-associated proteins. Physiologically, the protein level of Sirt1 is increased during osteoblast differentiation leading to the upregulation of Runx2 expression as well as activity [75, 76] that promote osteoblast differentiation. Interestingly, Sirt1 has also been reported to negatively regulate adipocyte differentiation. Sirt1 protein physically interacts with PPAR $\gamma$ to recruit nuclear receptor corepressor to its target promoters $[77,78]$ thus inhibiting PPAR $\gamma$ target gene expression. Depletion of Sirt1 both in vitro and in vivo shifts MSC commitment from osteoblasts to adipocytes [75, 76, 79]. Besides, the importance of Sirt1 in maintaining normal skeleton remodeling also lies in its ability to modulate BM inflammatory state by inhibiting NF- $\kappa \mathrm{B}$ signal [79]. In aged BM, accumulated ROS represses both the expression and the enzymatic activity of Sirt1 [73, 74] consequently shifting MSCs differentiation to favor adipocytes.

Another redox-sensitive factor that mediates the effects of ROS on MSC differentiation balance is Forkhead box $\mathrm{O}$ (FoxO), a transcription factor that is known to modulate cellular response to oxidative stress by up-regulating free radical scavenging enzymes such as manganese superoxide dismutase (Mn-SOD) and Catalase. FoxO-mediated transcription requires association with $\beta$-catenin, a scaffold protein that is also required for the transcriptional activity of the Tcf family of transcription factors (TCF), which are the downstream effectors of the $\mathrm{Wnt} / \beta$-catenin signaling pathway $[80,81]$. $\mathrm{Wnt} / \beta$-catenin pathway is one of the most indispensible signaling pathways for osteogenesis of MSCs. In addition to promoting osteoblast related gene expression, the importance of this signaling pathway lies in repressing the expression and transcriptional activity of adipogenic factors, PPAR $\gamma$ and $\mathrm{C} / \mathrm{EBP} \alpha$ [34]. Increased oxidative stress in pathological BM activates FoxOs, which in turn attenuate $\mathrm{Wnt} / \beta$-catenin signaling by diverting the limited pool of $\beta$-catenin from TCF- to FoxO-mediated transcription in osteoblastic cells, resulting in decreased bone formation and adipocyte accumulation. Consistently, mice lacking FoxO1, -3 and -4 in osteoblast progenitors exhibit increased osteoblast number, high bone mass as well as decreased adiposity in BM that is typical of old age $[80,81]$.

Table 1. miRNAs involved in TNF $\alpha$-mediated repression of osteoblast differentiation

\begin{tabular}{|c|c|c|c|}
\hline microRNAs & Targets & Comments & Reference \\
\hline miR-21 & Spry1 & $\begin{array}{l}\text { miR-21, positive regulator of osteoblast differentiation by targeting } \\
\text { Spry1, is down-regulated by TNF } \alpha \text { in OVX mice. }\end{array}$ & [92] \\
\hline miR-23 & Fas & $\begin{array}{l}\text { TNF } \alpha \text { induces osteoblast apoptosis partly by down-regulating miR- } \\
23 \text { expression, which inhibits apoptosis by targeting Fas. }\end{array}$ & [94] \\
\hline $\operatorname{miR}-3077-5 p$ & HOXA10 & $\begin{array}{l}\text { TNF } \alpha \text { promotes miR-3077-5p expression through NF- } \mathrm{B} \text { signaling } \\
\text { pathway, which then shifts MSCs fate to favor adipocytes over } \\
\text { osteoblasts by targeting HOXA10. }\end{array}$ & [93] \\
\hline miR-705 & Runx2 & $\begin{array}{l}\text { TNF } \alpha \text { promotes miR- } 705 \text { expression through NF- } \kappa \text { B signaling } \\
\text { pathway, which then shifts MSCs fate to favor adipocyte over } \\
\text { osteoblast by targeting Runx } 2 \text {. }\end{array}$ & [93] \\
\hline miR-155 & SOCS1 & $\begin{array}{l}\text { miR- } 155 \text { was induced in TNF } \alpha \text { treated pre-osteoblasts, which then } \\
\text { partly mediates the inhibitory effect of TNF } \alpha \text { on osteogenesis by } \\
\text { targeting SOCS } 1 \text {. }\end{array}$ & [95] \\
\hline
\end{tabular}

\section{Inflammatory cytokines}

Local or systemic increase in the concentration of proinflammatory cytokines in BM under pathological conditions lead to complex deregulation of bone metabolism that favors bone destruction by increasing osteoclast differentiation and activation [82, 83]. However, osteoblast-mediated bone formation under such circumstances cannot compensate for bone resorption suggesting direct inhibitory effect of pro-inflammatory cytokines on osteoblastogenesis [45]. TNF $\alpha$ has been reported to act upstream of other cytokines and is a major player in chronic inflammation-induced bone loss. This pro-inflammatory cytokine negatively regulates bone formation via repressing the commitment and the maturation of osteoblasts at multiple levels. In vitro studies found that TNF $\alpha$ activates NF- $\mathrm{KB}$ signal, which then inhibits Runx 2 mRNA transcription and promotes its 
protein degradation in smurf1/2-mediated proteosomedependent manner [84, 85]. BMP2/Smads signal in osteoblasts protects Runx2 protein from Smurf-catalyzed proteolysis by stimulating its acetylation [86]. However, $\mathrm{TNF} \alpha$ also blocks BMP2 signaling pathway and overrides its protective effect on Runx2 by up-regulating Smad7 and/or promoting proteolysis of Smads [87-89]. In addition, TNF $\alpha$ down-regulates both the expression and activity of another osteogenic key factor, Osterix (Osx) through the MEK1/ERK1 signaling cascade [90, 91].

Increasing numbers of evidence link microRNAs (miRNAs) to TNF $\alpha$-regulated bone metabolism. Studies that investigated miRNAs involved in TNF $\alpha$-mediated repression of osteogenesis are shown in Table 1. Among these, OVX mouse model studies clearly demonstrated the important role of miRNAs in the pathological process of osteogenesis [92-95]. High level of TNFa in the BM of OVX mouse models has been confirmed to modulate the expression levels of miR-21, miR-3077-5P, and miR-705. miR-21 promotes osteoblast differentiation by targeting Spry1, a negative regulator of osteogenesis [92]. Suppressing miR-21 by $\mathrm{TNF} \alpha$ partly explains the inhibitory effect of this cytokine on osteogenesis. Another study found that TNF $\alpha$ promotes the expression of miR3077-5P and miR-705 in osteoporotic BM in OVX mouse models via NF- $\mathrm{kB}$ signaling pathway. Both miR-705 and miR-3077-5p inhibit osteoblast differentiation by targeting HOXA10 and Runx2, respectively [93]. Consequently, redundant miR-705 and miR-3077-5p caused by TNF $\alpha$ shift MSC cell lineage commitment to adipocyte in osteoporotic bone marrow [93]. These findings not only provide new insights into the etiology of osteoporosis at the post-transcriptional level, but also suggest novel potential therapeutic targets to treat osteoporosis as well as for the use of stem cell-mediated regenerative medicine.

\section{Excessive adipose tissue}

Recent studies have expanded our understanding of the function of $\mathrm{BM}$ adipose tissue as an endocrine organ capable of secreting different factors to regulate bone metabolism. In vitro assays showed that osteoblastic differentiation is inhibited in adipocyte-conditioned media or when co-cultured with adipocytes [96, 97] indicating the negative effect of adipocyte-secreted factors on osteoblastogenesis. As excessive fat was found in osteoporotic BM [1-8], it is speculated that the adipose tissue might further deteriorate BM microenvironment in a paracrine and/or endocrine manner [96, 98]. Factors secreted by adipocytes are listed as free fatty acids [96], adipokines [98], and exosomes [99], which are discussed below.
As natural ligands for PPAR $\gamma$, excess FFAs and their metabolites released into the BM activate PPAR $\gamma$ in MSCs, osteo-progenitors and osteoblasts [100-102]. PPAR $\gamma$ belongs to the nuclear receptor (NR) superfamily of transcription factors. In osteoblasts, the transcriptional activity of PPAR $\gamma$ is inhibited by its co-repressors [103]. Upon ligand activation, co-repressors are degraded while co-activators are recruited to PPAR $\gamma$, which then induces target gene expression and shifts the differentiation program to favor adipocytes [103]. Furthermore, activation of PPAR $\gamma$ during osteoblastogenesis inhibits the transcriptional activity of Runx 2 and turns osteoblasts into adipocytes [104-106]. However, these observations were only made in vitro. The effect of additional FFAs in osteoporotic BM needs further investigation.

Cytokines secreted from adipose tissue are termed adipokines; these include leptin, adiponectin, chemerin, omentin, and resistin, which have profound effects on surrounding cells [98]. In osteoporotic BM of postmenopausal women, the levels of leptin and adiponectin were significantly lower [107]. Besides, the affinity of leptin receptors on osteoporotic MSCs is also lower [108] indicating decreased leptin signal activity. However, the action of leptin on the bone appears to have both positive and negative consequences and is not fully understood. Several in vitro studies have confirmed the positive effects of leptin on osteoblast proliferation, differentiation, and suppression of osteoblast-dependent osteoclast recruitment, while negatively regulating adipogenesis via their receptors expressed on both lineages [109-112]. A number of studies in mice have indicated the negative influence of leptin on bone metabolism and function because of its ability to enhance the sympathetic output to bone from the hypothalamus [113]. However, clinical investigation demonstrated a positive link between serum leptin levels and bone mineral density (BMD), especially in women. Yet a number of other studies suggested no correlation [114]. Adiponectin is another adipose secreted adipokine with critical roles in glucose metabolism and energy homeostasis [115]. In vitro studies also found that this adipokine promotes osteoblastogenesis but negatively regulates adipogenesis [116-118]. However, in vivo studies with adiponectin-deficient mice showed agedependent increase in trabecula volume and number suggesting that adiponectin has both direct and indirect effects on bone in vivo, and is also a likely contributor to bone mass [118]. The role of other adipokines in MSC differentiation is less clear, however, recent findings suggest that most of these adipokines may play a role in regulating bone metabolism and remodeling [98].

Cultured adipocytes are reported to release exosomes that may regulate the metabolism of recipient cells [119]. Exosomes are membrane vesicles that carry a cargo of 
proteins, lipids and nuclear acids, which may differ based on adipogenic stages and/or under pathological conditions $[120,121,122]$. Adipocyte-secreted exosomes are demonstrated to contain specific transcripts (such as adiponectin [123] and aP2 [124]) and miRNAs [119, 99], which are transported into recipient cells and are involved in modulating gene expression as well as energy metabolism. Several studies demonstrated that adipocyte derived exosomes mediate cell-cell communication that might play a role in controlling lipogenesis and cell size [121], obesity related disease [120] and nonalcoholic fatty liver disease [125]. It is possible that exosomes from bone marrow adipose tissue under osteoporotic conditions carry different cargo to affect the osteoblastic/adipocytic fate of bone marrow MSCs. Additional research is needed to investigate the biological significance of exosomemediated cell communication in cell differentiation and metabolism under both physiological and pathological conditions

\section{Conclusion and therapeutic implications}

The stem cell differentiation paradigm is based on the progression of cells through generations of daughter cells that eventually become restricted and committed to one lineage resulting in fully differentiated cells. As the commitment and differentiation process is tightly controlled by their supporting microenvironment, pathological environmental signals alter the differentiation pathway thus resulting in abnormal differentiation and tissue dysfunction. The BM microenvironment changes progressively during pathological conditions linked to osteoporosis, and are characterized by increased oxidative stress, chronic inflammation, suppressed osteogenic signals and elevated osteoblastic inhibitors. These pathological environmental factors contribute to a shift in MSC differentiation to favor adipocytes over osteoblasts. As a consequence of marrow obesity, pathological bone marrow is aggravated by excessive FFAs and abnormal adipokine spectrum. Excessive FFAs in the bone marrow promote oxidative stress and inflammation, initiating a vicious cycle that leads to bone destruction. These biochemical environmental factors together pre-determine adipogenic fate of bone marrow MSCs and repress osteogenic pathway that ultimately lead to bone loss with marrow fat accumulation.

Traditional therapeutic strategies to combat bone loss and osteoporosis have centered almost exclusively on anti-bone resorption agents designed to prevent further bone breakdown in patients already at high risk for fracture. As preventing further bone resorption cannot ameliorate low BMD in these patients, attention has been focused on the development of anabolic agents to actively rebuild lost bone mass. As the activities of MSCs are controlled by the local environment, microenvironment based therapy would be a promising strategy to rebuild bone mass. This strategy is best exemplified in the studies of intra-BM transplantation, which showed that agerelated osteoporosis was prevented and partly treated by injecting youthful BM cells directly into the BM cavity of aged animals [18, 19]. Since oxidative stress and inflammation play central roles in aggravating the BM microenvironment, targeting key factors in BM oxidation and inflammation would also help improve the BM microenvironment. Genetic animal models with Sirt1 [79], T-cells and TNF $\alpha[47,49,50]$ as targets have implicated their therapeutic roles in the clinical treatment of osteoporosis. Considering the reciprocal relationship between adipocytes and osteoblasts, as well as the contributing role of adipose tissue in the pathological changes of BM microenvironment, targeting adipocyte for bone disease would be an alternative therapeutic strategy. Potential targets for this strategy could be leptin, PPAR $\gamma$ [126], NF-kB and factors involved in insulin sensitivity [89].

Additional mechanisms should be investigated to explore alternate strategies to treat osteoporosis. For instance, the mechanisms that facilitate the cross-talk between BM cells and environmental factors are not known. The regulatory network among environmental signals, cellular transduction pathways, transcriptional factors and target genes are far from understood. These missing pieces of this regulatory network need further investigation, which is crucial for identifying therapeutic targets for such a debilitating disease.

\section{Acknowledgement}

This work was supported by National Natural Science Foundation of China (No. 81401844).

\section{Conflict of interest.}

The authors declare that they have no conflict of interest.

\section{Reference}

[1] Rozman C, Feliu E, Berga L, Reverter JC, Climent C, Ferran MJ (1989). Age-related variations of fat tissue fraction in normal human bone marrow depend both on size and number of adipocytes: a stereological study. Exp Hematol, 17:34-37.

[2] Justesen J, Stenderup K, Ebbesen EN, Mosekilde L, Steiniche T, Kassem M (2001). Adipocyte tissue volume in bone marrow is increased with aging and in patients with osteoporosis. Biogerontology, 2:165-71.

[3] Jee WSS, Wronski TJ, Morey ER, Kimmel DB. Effects of spaceflight on trabecular bone in rats (1983). Am J Physiol, 244:R310-4. 
[4] Ahdjoudj S, Lasmoles F, Holy X, Zerath E, Marie PJ (2002). Transforming growth factor beta2 inhibits adipocyte differentiation induced by skeletal unloading in rat bone marrow stroma. J Bone Miner Res, 17:66877.

[5] Li X, Jin L, Cui Q, Wang GJ, Balian G (2005). Steroid effects on osteogenesis through mesenchymal cell gene expression. Osteoporos Int, 16:101-8.

[6] Cui Q, Wang GJ, Balian G (2000). Pluripotential marrow cells produce adipocytes when transplanted into steroidtreated mice. Connect Tissue Res, 41:45-56.

[7] van Staa TP, Leufkens HG, Cooper C (2002). The epidemiology of corticosteroid-induced osteoporosis: a metaanalysis. Osteoporos Int, 13:777-87.

[8] Tuominen JT, Impivaara O, Puukka P, Ronnemaa T (1999). Bone mineral density in patients with type 1 and type 2 diabetes. Diabetes Care, 22:1196-200.

[9] Verma S, Rajaratnam JH, Denton J, Hoyland JA, Byers RJ (2002). Adipocytic proportion of bone marrow is inversely related to bone formation in osteoporosis. $\mathrm{J}$ Clin Pathol, 55:693-8.

[10] Yeung DK, Griffith JF, Antonio GE, Lee FK, Woo J, Leung PC (2005). Osteoporosis is associated with increased marrow fat content and decreased marrow fat unsaturation: a proton MR spectroscopy study. J Magn Reson Imaging, 22:279-85.

[11] Bennett JH, Joyner CJ, Triffit JT, Owen ME (1991). Adipocytic cells cultured from marrow have osteogenic potential. J Cell Sci, 99:131-9.

[12] Beresford JN, Bennett JH, Devlin C, Leboy PS, Owen ME (1992). Evidence for an inverse relationship between the differentiation of adipocytic and osteogenic cells in rat marrow stromal cell cultures. J Cell Sci, 102:341-51.

[13] Muruganandan S, Roman AA, Sinal CJ (2009). Adipocyte differentiation of bone marrow-derived mesenchymal stem cells: cross talk with the osteoblastogenic program. Cell Mol Life Sci, 66:236-53.

[14] Moore KA, Lemischka IR (2006). Stem cell and their niches. Science, 311: 1880-5.

[15] Kuhn NZ, Tuan RS (2010). Regulation of stemness and stem cell niche of mesenchymal stem cells: implications in tumorigenesis and metastasis. J Cell Physiol, 222: 268-77.

[16] Stein GS, Lian JB (1993). Molecular mechanisms mediating proliferation/differentiation interrelationships during progressive development of the osteoblast phenotype. Rndocr Rev, 14: 424-42.

[17] Ueda Y, Inaba M, Takada K, Fukui J, Sakaguchi Y, Tsuda $\mathrm{M}$ et al (2007). Induction of senile osteoporosis in normal mice by intra-bone marrow-bone marrow transplantation from osteoporosis-prone mice. Stem Cell, 25: 1356-63.

[18] Takada K, Inaba M, Ichioka N, Ueda Y, Taira M, Baba $S$ et al (2006). Treatment of senile osteoporosis in SAMP6 mice by intra-bone marrow injection of allogeneic bone marrow cells. Stem Cells, 24: 399-405.

[19] Ichioka N, Inaba M, Kushida T, Esumi T, Takahara K, Inaba $\mathrm{K}$ et al (2002). Prevention of senile osteoporosis in SAMP6 mice by intrabone marrow injection of allogeneic bone marrow cells. Stem Cells, 20: 542-51.
[20] Chen XD, Dusevich V, Feng JQ, Manolagas SC, Jilka RL (2007). Extracellular matrix made by bone marrow cells facilitates expansion of marrow-derived MSCs and prevents their differentiation into osteoblast. J Bone Miner Res, 22:1943-56.

[21] Halleux C, Sottile V, Gasser JA, Seuwen K (2001). Multi-lineage potential of human mesenchymal stem cells following clonal expansion. J Musculoskelet Neuronal Interact, 2:71-6.

[22] Muraglia A, Cancedda R, Quarto R (2000). Clonal mesenchymal progenitors from human bone marrow differentiate in vitro according to a hierarchical model. $\mathbf{J}$ Cell Sci, 113:1161-6.

[23] Tang Y, Wu X, Lei W, Pang L, Wan C, Shi Z (2009), TGFbeta1-induced migration of bone mesenchymal stem cells couples bone resorption with formation. Nat Med, 15:757-65.

[24] Wang YK, Chen CS (2013). Cell adhesion and mechanical stimulation in the regulation of mesenchymal stem cell differentiation. J Cell Mol Med, 17:823-32.

[25] McBeath R, Pirone DM, Nelson CM, Bhadriraju K, Chen CS (2004). Cell shape, cytoskeletal tension and RhoA regulate stem cell lineage commitment. Dev Cell, 6:483-95

[26] Nakashima A, Katagiri T, Tamura M (2005). Cross-talk between Wnt and bone morphogenetic protein 2 (BMP2) signaling in differentiation pathway of $\mathrm{C} 2 \mathrm{C} 12$ myoblasts. J Biol Chem, 280: 37660-8

[27] Zmurovic N, Cappellen D, Rohner D, Susa M (2004). Coordinated activation of notch, Wnt, and transforming growth factor-beta signaling pathways in bone morphogenic protein 2-induced osteogenesis. Notch target gene Hey1 inhibits mineralization and Runx2 transcriptional activity. J Biol Chem, 279: 37704-15

[28] Almeida M, Han L, Bellido T. Manolagas SC, Kousteni $S$ (2005). Wnt proteins prevent apoptosis of both uncommitted osteoblast progenitors and differentiated osteoblasts by beta-catenin-dependent and -independent signaling cascades involving Src/ERK and phosphatidylinositol 3-kinase/AKT. J Biol Chem, 280: 41342-51.

[29] Lee KS, Hong SH, Bae SC (2002). Both Smad and p38 MAPK pathways play a crucial role in Runx2 expression following induction by transforming growth factor-beta and bone morphogenetic protein. Oncogene, 21: 715663.

[30] Miraoui H, Oudina K, Petite H, Tanimoto Y, Moriyama K, Marie PJ (2009). Fibroblast growth factor receptor 2 promotes osteogenic differentiation in mesenchymal cells via ERK1/2 and protein kinase $\mathrm{C}$ signaling. J Biol Chem. 284: 4897-904

[31] Wang Y, Bikle DD, Chang W (2013). Autocrine and paracrine actions of IGF-1 signaling in skeletal development. Bone Res, 1: 249-59.

[32] Choy L, Derynck R (2003). Transforming growth factorbeta inhibits adipocyte differentiation by $\operatorname{smad} 3$ interaction with CCAAT/enhancer-binding protein $(\mathrm{C} / \mathrm{EBP})$ and repressing $\mathrm{C} / \mathrm{EBP}$ transactivation function. J Biol Chem, 278: 9609-19. 
[33] Takara I, Mihara M, Suzawa M, Ohtake F, Kobayashi S, Igarashi $M$ et al (2007). A histone lysine methyltransferase activated by non-canonical Wnt signaling suppresses PPAR-gamma transactivation. Nat Cell Biol, 9:1273-85.

[34] Kang S, Bennett CN, Gerin I, Rapp LA, Hankenson KD, Macdougald OA (2007). Wnt signaling stimulates osteoblastogenesis of mesenchymal precursors by suppressing CCAAT/enhancer-binding protein alpha and peroxisome proliferator-activated receptor gamma. $\mathbf{J}$ Biol Chem, 282:14515-24.

[35] Looker AC, Wahner HW, Dunn WL, Calvo MS, Harris TB, Heyse SP et al (1998). Updated data on proximal femur bone mineral levels of US adults. Osteoporos Int. 8: 468-89.

[36] Almeida M, Han L, Martin-Millan M, Plotkin LI, Stewart SA, Roberson PK et al (2007). Skeletal involution by age-associated oxidative stress and its acceleration by loss of sex steroids. J Biol Chem, 283: 27285-97.

[37] Wauquier F, Leotoing L, Coxam V, Guicheux J, Wittrant $\mathrm{Y}$ (2009). Oxidative stress in bone remodeling and disease. Treads Mol Med. 15: 468-77.

[38] Chung HY, Sung B, Jung KJ, Zou Y, Yu BP (2006). The molecular inflammatory process in aging. Antioxid Redox Signal, 8: 572-81.

[39] Gloire G, Piette J (2009). Redox regulation of nuclear post-translational modifications during NF-kappaB activation. Antioxid Redox Signal, 11: 2209-22.

[40] Kabe Y, Ando K, Hirao S, Yoshida M, Handa H (2005). Redox regulation of NF-kappaB activation: distinct redox regulation between the cytoplasm and the nucleus. Antioxid Redox Signal, 7: 395-403.

[41] Gilmore TD, Koedood M, Piffat KA, White DW (1996). Rel/NF-kappaB/IkappaB proteins and cancer. Oncogene, 13: $1367-78$

[42] Ghosh S, May MJ, Kopp EB (1998). NF-кB and REL proteins: evolutionary conserved mediators of immune responses. Annu Rev Immunol, 16: 225-60.

[43] Sul OJ, Ke K, Kim WK, Kim SH, Lee SC, Kim HJ (2012). Absence of MCP-1 leads to elevated bone mass via impaired actin ring formation. J Cell Physiol, 227: 1619-27.

[44] Atashi F, Modarressi A, Pepper MS (2015). The role of reactive oxygen species in mesenchymal stem cell adipogenic and osteogenic differentiation: a review. Stem Cell Dev, 24: 1150-63.

[45] Weitzmann MN, Pacifici R (2006). Estrogen deficiency and bone loss: an inflammatory tale. J Clin Inves, 116: 1186-94.

[46] Ghisletti S, Meda C, Maggi A, Vegeto E (2005). 17betaestradiol inhibits inflammatory gene expression by controlling NF-kappaB intracellular localization. Mol Cell Biol, 25: 2957-68.

[47] Pfeilschifter J, Köditz R, Pfohl M, Schatz H (2002). Changes in Proinflammatory cytokine activity after menopause. Endocr Rev, 23: 90-119.

[48] Li JY, Tawfeek H, Bedi B, Yang X, Adams J, Gao KY (2011) Ovariectomy disregulates osteoblast and osteoclast formation through the T-cell receptor CD40 ligand. Proc Natl Acad Sci U S A, 108: 768-73.

[49] Gilbert LC, Rubin J, Nanes MS (2005). The p55 TNF receptor mediates TNF inhibition of osteoblast differentiation independently of apoptosis. An J Physiol Endocrinol Metab, 288: E1011-8.

[50] Gao Y, Qian WP, Dark K, Toraldo G, Lin AS, Guldberg RE (2004). Estrogen prevents bone loss through transforming growth factor beta signaling in T cells. Proc Natl Acad Sci U S A, 101: 16618-23.

[51] Galine R, Garcia T (1997). Estrogen receptor impairs interlukin- 6 expression by preventing protein binding on the NF-kappaB site. Nucleic Acids Res, 25: 2424-9.

[52] Biswas DK, Singh S, Shi Q, Pardee AB, Lglehart JD (2005). Crossroads of estrogen receptor and NF-kappaB signaling. Sci STKE, pe27.

[53] De Bosscher K, Vanden Berghe W, Haegeman G (2006). Cross-talk between nuclear receptors and nuclear factor kappaB. Oncogene, 25: 6868-86.

[54] Speir E, Yu ZX, Takeda K, Ferrans VJ, Cannon RO 3rd (2000). Competition for p300 regulates transcription by estrogen receptors and nuclear factor-kappaB in human coronary smooth muscle cells. Circ Res, 87: 1006-11.

[55] Chen Y, Chen L, Yin Q, Gao H, Dong P, Zhanf X et al (2013). Reciprocal interferences of TNF- $\alpha$ and Wnt $1 / \beta$ catenin signaling axes shift bone marrow-derived stem cells towards osteoblast lineage after ethanol exposure. Cel Physiol Biochem, 32:755-65.

[56] Chen Y, Gao H, Yin Q, Chen L, Dong P, Zhang X (2013), ER stress activating ATF4/CHOP-TNF- $\alpha$ signaling pathway contributes to alcohol-induced disruption of osteogenic lineage of multipotential mesenchymal stem cell. Cell physiol Biochem, 32:743-54.

[57] Feng YL, Tang XL (2014). Effect of glucocorticoidinduced oxidative stress on the expression of Cbfa1. Chem Biol Interact, 25:26-31.

[58] Abu-Amer Y (2005). Advances in osteoclast differentiation and function. Curr Drug Targets Immune Endocr Metabol Disord, 5:347-55.

[59] Krum SA, Chang J, Miranda-Carboni G, Wang CY (2010). Novel functions for NFKB: inhibition of bone formation. Nat Rev Rheumatol, 6: 607-11.

[60] Moerman EJ, Teng K, Lipschitz DA, Lecka- Czernik B (2004). Aging activates adipogenic and suppresses osteogenic programs in mesenchymal marrow stroma/stem cells: the role of PPAR-gamma2 transcription factor and TGF-beta/BMP signaling pathways. Aging Cell, 3:379-89.

[61] Benisch P, Schilling T, Klein-Hitpass L, Frey SP, Seefried L, Raaijmakers N (2012). The transcriptional profile of mesenchymal stem cell populations in primary osteoporosis is distinct and shows overexpression of osteogenic inhibitors. Plos One, 7:e45142.

[62] Haasters F, Docheva D, Gassner C, Popov C, Böcker W, Mutschler W et al (2014). Mesenchymal stem cells from osteoporotic patients receal reduced migration and invasion upon stimulation with BMP-2 or BMP-7. Biochem Biophys Res Commun, 452: 118-23.

[63] Prall WC, Haasters F, Heggebö J, Polzer H, Schwarz C, Gassner C et al (2013). Mesenchymal stem cells from 
osteoporotic patients feature impaired signal transduction but sustained osteoinduction in response to BMP-2 stimulation. Biochem Biophys Res Commun, 440: 617-22.

[64] Romacho T, Elsen M, Röhrborn D, Eckel J (2014). Adipose tissue and its role in organ crosstalk. Acta Physiol (Oxf), 210:733-53.

[65] Lee BC, Lee J (2014). Cellular and molecular players in adipose tissue inflammation in the development of obesity-induced insulin resistance. Biochim Biochys Acta, 1842:446-62.

[66] Shen WJ, Liu LF, Patel S, Kraemer FB (2011). Hormone-sensitive lipase-knockout mice maintain high bone density during aging. FASEB J, 25:2722-30.

[67] Tchkonia T, Corkey BE. Kirkland JL (2006). Current views of the fat cell as an endocrine cell: lipotoxicity. Endocrine Updates. 26: 105-18.

[68] Guo W, Pirtskhalava T, Rchkonia T, Xie W, Thomou T, Han J (2007). Aging results in paradoxical susceptibility of fat cell progenitors to lipotoxicity. Am J Physiol Endocrinol Metab, 292:E1041-50

[69] Chen Q, Liu K, Robinson AR, Clauson CL, Blair HC, Robbins PD et al (2013). DNA damage drives accelerated bone aging via an NF- $\mathrm{B}$-dependent mechanism. J Bone Miner Res, 28:1214-28.

[70] Nicolaije C, Diderich KE, Botter SM, Priemel M, Waarsing JH, Day JS (2012). Age-related skeletal dynamics and decrease in bone strength in DNA repair deficient male trichothiodystrophy mice. PloS One, 7:e35246

[71] Bai XC, Lu D, Bai J, Zheng H, Ke ZY, Li XM et al (2004). Oxidative stress inhibits osteoblastic differentiation of bone cells by ERK and NF-kappa B. Biochem Biophys Res Commun, 314:197-207.

[72] Turker I, Zhang Y, Rehman J (2007). Oxidative stress as a regulator of adipogenesis. FASEB, 21:830-5.

[73] Cencioni C, Spallotta F, Martelli F, Valente S, Mai A, Zeiher AM et al (2013). Oxidative stress and epigenetic regulation in ageing and age-reglated disease. Int $\mathrm{J}$ Mol Sci, 14:17643-63.

[74] Afanas'ev I (2013). New nucleophilic mechanisms of ros-dependent epigenetic modifications: camparison of aging and cancer. Aging Dis, 5: 52-62.

[75] Shakibaei M, Shayan P, Busch F, Aldinger C, Buhrmann C, Lueders C et al (2012). Resveratrol mediated modulation of Sirt-1/Runx2 promotes osteogenic differentiation of mesenchymal stem cells: potential role of Runx2 deacetylation. PLoS One, 7:e35712.

[76] Tseng PC, Hou SM, Chen RJ, Peng HW, Hsieh CF, Kuo ML et al (2011). Resveratrol promotes osteogenesis of human mesenchymal stem cells by upregulation RUNX2 gene expression via the SIRT1/FOXO3A axis. J Bone Miner Res, 26: 2552-63.

[77] Bäckesjö CM, Li Y, Lindgren U, Haldosén LA (2006). Activation of Sirt1 decreases adipocyte formation during osteoblast differentiation of mesenchymal stem cells. J Bone Miner Res, 21: 993-1002.

[78] Han L, Zhou R, Niu J, McNutt MA, Wang P, Tong T (2010). SIRT1 is regulated by a PPAR $\{\gamma\}-\operatorname{SIRT1}$ negative feedback loop associated with senescence. Nucleic Acids Res, 38: 7458-71.

[79] Edwards JR, Perrien DS, Fleming N, Nyman JS, Ono K, Connelly L (2013). Silent information regulator (Sir)T1 inhibits NF- $\kappa \mathrm{B}$ signaling to maintain normal skeletal remodeling. J Bone Miner Res, 28:960-9.

[80] Almeida M, Han L, Martin-Millan M, O`Brien CA, Manolagas SC (2007) Oxidative stress antagonizes Wnt signaling in osteoblast precursors by diverting betacatenin from $\mathrm{T}$ cell factor- to forkhead box O- mediated transcription. J Biol Chem, 282:27298-305.

[81] Iyer S, Ambrogini E, Bartell SM, Han L, Roberson PK, de Cabo R et al (2013). FOXOs attenuate bone formation by suppressing Wnt signaling. J Clin Invest, 124:340919.

[82] Jimi E, Aoki K, Saito H, D'Acquisto F, May MJ, Nakamura I et al (2004). Selective inhibition of NFkappa B blocks osteoclastogenesis and prevents inflammatory bone destruction in vivo. Nat Med. 10: $617-24$

[83] Tanizawa T, Yamaguchi A, Uchiyama Y, Miyaura C, Ikeda T, Ejiri S et al (2000). Reduction in bone formation and elevated bone resorption in ovariectomized rats with special reference to acute inflammation. Bone, 26: 43-53.

[84] Gilbert L, He X, Parmer P, Rubin J, Drissi H, van Wijnen AJ et al (2002). Expression of the osteoblast differentiation factor RUNX2 (Cbfa1/AML3/Pebp2alpha A) is inhibited by tumor necrosis factor-alpha. J Biol Chem, 277:2695-701.

[85] Kaneki H, Guo R, Chen D, Yao Z, Schwarz EM, Zhang YE et al (2006). Tumor necrosis factor promotes Runx2 degradation through up-regulation of Smurf1 and Smurf2 in osteoblasts. J Biol Chem, 281:4326-33.

[86] Jeon EJ, Lee KY, Choi NS, Lee MH, Kim HN, Jin YH (2006). Bone morphogenetic protein-2 stimulates Runx2 acetylation. J Biol Chem, 281:16502-11.

[87] Eliseev RA, Schwarz EM, Zuscik MJ, O'Keefe RJ, Drissi H, Rosier RN (2006). Smad7 mediates inhibition of Saos2 osteosarcoma cell differentiation by NFkappaB. Exp Cell Res, 312:40-50.

[88] GuoR, Yamashita M, Zhang Q, Chen D, Reynolds DG, Awad HA (2008). Ubiguitin ligase Smurf1 mediates tumor necrosis factor-induced systemic bone loss by promoting proteasomal degradation of bone morphogenetic signaling proteins. J Biol Chem, 283:23084-92.

[89] Li Y, Li A, Strait L, Zhang H, Nanes MS, Weitzmann MN (2007). Endogenous TNFalpha lowers maximum peak bone mass and inhibits osteoblastic Smad activation through NF-kappaB. J Bone Miner Res, 22:646-55.

[90] Lu X, Beck GR Jr, Gilbert LC, Camalier CE, Bateman NW, Hood BL et al (2011). Identification of the homeobox protein Prx1 (MHox, Prrx-1) as a regulator of osterix expression and mediator of tumor necrosis factor $\alpha$ action in osteoblast differentiation. J Bone Miner Res, 26:209-19.

[91] Lu X, Gilbert L, He X, Rubin J, Nanes MS (2006). Transcriptional regulation of the osterix (Osx, Sp7) promoter by tumor necrosis factor identifies disparate 
effects of mitogen-activated protein kinase and NF kappa B pathways. J Biol Chem, 281:6297-306.

[92] Yang N, Wang G, Hu C, Shi Y, Liao L, Shi S (2013). Tumor necrosis factor $\alpha$ suppresses the mesenchymal stem cell osteogenesis promoter miR-21 in estrogen deficiency-induced osteoporosis. J Bone Miner Res, 28: 559-73.

[93] Liao L, Yang X, Su X, Hu C, Zhu X, Yang N et al (2013). Redundant miR-3077-5p and miR-705 mediate the shift of mesenchymal stem cell lineage commitment to adipocyte in osteoporosis bone marrow. Cell Death Dis, 4:e600.

[94] Dong J, Cui X, Jiang Z, Sun J (2013). MicroRNA-23a modulates tumor necrosis factor-alpha-induced osteoblasts apoptosis by directly targeting Fas. J Cell Biochem, 144: 2738-45.

[95] Wu T, Xie M, Wang X, Jiang X, Li J, Huang H (2012). miR-155 modulates TNF- $\alpha$-inhibited osteogenic differentiation by targeting SOCS1 expression. Bone, 51: 498-505.

[96] Dong X, Bi L, He S, Meng G, Wei B, Jia S et al (2014). FFAs-ROS-ERK/P38 pathway plays a key role in adipocyte lipotoxicity on ostoeblasts in co-culture. Biochimie, 101:123-31.

[97] Maurin A, Chavassieux P, Frappart L, Delmas P, Serre C, meunier P (2000). Influence of mature adipocytes on osteoblast proliferation in human promary cocultures. Bone, 26:485-9.

[98] Scotece M, Conde J, Abella V, López V, Pino J, Lago D et al (2014). Bone metabolism and adipokines: are there perspectives for bone diseases drug discovery? Exper Opin Drug Discov, 24:1-13.

[99] Müller G, Schneider M, Biemer-Daub G, Wied S (2011). Microvesicles released form rat adipocytes and harboring glycosylphosphatidylinositol-anchored proteins transfer RNA stimulating lipid synthesis. Cell Signal, 23:1207-23.

[100] Diascro DD Jr, Vogel RL, Johnson TE, Witherup KM, Pitzenberger SM, Rutledge SJ et al (1998). High fatty acid content in rabbit serum is responsible for the differentiation of osteoblasts into adipocyte-like cells. $\mathbf{J}$ Bone Miner Res. 13: 96-106.

[101] Lecka-Czernik B, Moerman EJ, Grant DF, Lehmann JM, Manolagas SC, Jilka RL (2002). Divergent effects of selective peroxisome proliferator-activated receptorgamma 2 ligands on adipocyte versus osteoblast differentiation. Endocrinology. 143: 2376-84.

[102] Viccica G, Francucci CM, Marcocci C (2010). The role of PPAR $\gamma$ for the osteoblastic differentiation. J Endocrinol Invest. 33: 9-12.

[103] Tontonoz P, Spiegelman BM (2008). Fat and beyond: the diverse biology of PPARgamma. Annu Rev Biochem, 77:289-312.

[104] Yoshiko Y, Oizumi K, Hasegawa T, Minamizaki T, Tanne K, Maeda N et al (2010). A subset of oateoblasts express high endogenous levels of PPARgamma switches fate to adipocytes in the rat calvaria cell culture model. PLoS One, 26:e11782.

[105] Lecka-Czernik B, Gubrij I, Moerman EJ, Kajkenova O, Lipschitz DA, Manolagas SC et al (1999). Inhibition of
Osf2/Cbfa1 expression and terminal ostoeblast differentiation by PPARgamma2. J Cell Biochem, 74:357-71.

[106] Jeon MJ, Kim JA, Kwon SH, Kim SW, Park KS, Park SW (2003). Activation of peroxisome proliferatoractivated receptor-gamma inhibits Runx2-mediated transcription of osteocalcin in osteoblasts. J Biol Chem, 278:23270-7.

[107] Pino AM, Ríos S, Astudillo P, Fernández M, Figueroa O, Seitz G, et al (2010). Concentration of adipogenic and proinflammatory cytokines in the bone marrow supernatant fluid of osteoporotic women. J Bone Min Res, 25:492-498

[108] Hess R, Pino AM, Ríos S, Fernández M, Rodríguez JP (2005) High affinity leptin receptors are present in human mesenchymal stem cells (MSCs) derived from control and osteoporotic donors. J Cell Biochem, 94:507.

[109] Astudillo P, Ríos S, Pastenes L, Pino AM, Rodríguez JP (2008) Increased adipogenesis of osteoporotic humanmesenchymal stem cells (MSCs) characterized by impaired leptin action. J Cell Biochem, 103:1054-65.

[110] Thomas T, Gori F, Khosla S, Jensen MD, Burguera B, Riggs BL (1999). Leptin acts on human marrow stromal cells to enhance differentiation to osteoblasts and to inhibit differentiation to adipocytes. Endocrinology, 140:1630-8.

[111] Gordeladze JO, Drevon CA, Syversen U, Reseland JE (2002). Leptin stimulates human osteoblastic cell proliferation, de novo collagen synthesis, and mineralization: impact on differentiation markers, apoptosis, and osteoclastic signaling. Journal of Cellular Biochemistry, 85:825-36.

[112] Scheller EL, Song J, Dishowitz MI, Soki FN, Hankenson $\mathrm{KD}$, Krebsbach PH (2010). Leptin functions peripherally to regulate differentiation of mesenchymal progenitor cells. Stem Cells (Dayton, Ohio), 28:1071-80.

[113] Motyl KJ, Rosen CJ (2012). Understanding leptindependent regulation of skeletal homeostasis. Biochimie, 94:2089-96.

[114] Sadie-Van Gijsen H, Crowther NJ, Hough FS, Ferris WF (2013). The interrelationship between bone and fat: from cellular see-saw to endocrine reciprocity. Cell Mol Life Sci, 70:2331-49.

[115] Yamauchi T, Kamon J, Minokoshi Y, Ito Y, Waki H, Uchida $S$ et al (2002). Adiponectin stimulates glucose utilization and fatty-acid oxidation by activating AMPactivated protein kinase. Nat med, 8: 1288-95.

[116] Luo XH, Guo LJ, Yuan LQ, Xie H, Zhou HD, Wu XP et al (2005). Adiponectin stimulates human osteoblasts proliferation and differentiation via the MAPK signaling pathway. Exp Cell Res, 309:99-109.

[117] Shinoda Y, Yamaguchi M, Ogata N, Akune T, Kubota N, Yamauchi T (2006). Regulation of bone formation by adiponectin through autocrine/paracrine and endocrine pathways. J Cell Biochem, 99:196-208.

[118] Williams GA, Wang Y, Callon KE, Watson M, Lin JM, Lam JB (2009). in vitro and in vivo effects of adiponectin on bone. Endocrinology, 150:3603-10. 
[119] Sano S, Izumi Y, Yamaguchi T, Yamazaki T, Tanaka M, Shiota $M$ et al (2014). Lipid synthesis is promoted by hypoxic adipocyte-derived exosomes in 3T3-L1 cells. Biochem Biophys Res Commun, 445:327-33.

[120] Ferrante SC, Nadler EP, Pillai DK, Hubal MJ, Wang Z, Wang JM et al (2015). Adipocyte-derived exosomal miRNAs: a novel mechanism for obesity-related disease. Pediatr Res. 77: 447-54.

[121] Sano S, Izumi Y, Yamaguchi T, Yamazaki T, Tanaka M, Shiota M et al (2014). Lipid synthesis is promoted by hypoxic adipocyte-derived exosones in 3T3-L1 cells. Biochem Biophys Res Commun. 445: 327-33.

[122] Lee JE, Moon PG, Lee IK, Baek MC (2015). Proteomic Analysis of Extracellular Vesicles Released by Adipocytes of Otsuka Long-Evans Tokushima Fatty (OLETF) Rats. Protein J. 34: 220-35.
[123] Phoonsawat W, Aoki-Yoshida A, Tsuruta T, Sonoyama $\mathrm{K}$ (2014). Adiponectin is partially associated with exosomes in mouse serum. Biochem Biophys Res Commun. 448: 261-6.

[124] Ertunc ME, Sikkeland J, Fenaroli F, Griffiths G, Daniels MP, Cao H et al (2015). Secretion of fatty acid binding protein aP2 from adipocytes through a nonclassical pathway in response to adipocyte lipase activity. J Lipid Res. 56: 423-34.

[125] Koeck ES, Iordanskaia T, Sevilla S, Ferrante SC, Hubal MJ, Freishtat RJ et al (2014). Adipocyte exosomes induce transforming growth factor beta pathway dysregulation in hepatocytes: a novel paradigm for obesity-related liver disease. J Surg Res. 192: 268-75.

[126] Kawai M, Devlin MJ, Rosen CJ (2009). Fat targets for skeletal health. Nat Rev Rheumatol, 5:365-72. 